\title{
AUTOMATED DISRUPTION ASSISTANCE IN BRAZIL
}

\author{
Christian Gruber Delamare gruberdc@my.erau.edu \\ Douglas Cabrera Lopes cabrerd8@my.erau.edu \\ Patrice Ramos RAMOSP4@my.erau.edu \\ Raioni de Oliveira Santos DEOLIVR1@my.erau.edu \\ Leila Halawi halawil@erau.edu
}

\begin{abstract}
During the last decade, commercial aviation in Brazil has grown significantly, overcoming the number of 100 million passengers per year. The full operation represents a challenge for the air carriers, especially during flight disruptions. Besides the re-accommodation of the passengers into other flights, under certain circumstances, the ANAC 400 resolution requires the airlines to provide a series of material assistance. Meal, transport, and hotel make part of the exigences stated by the ANAC 400. Our study aims to analyze the current process that is mainly manual and propose to automatize several steps through a self-service solution. The researchers verified the potential adoption of the resolution through a survey where the vast majority of respondents are favorable for using self-services and avoid lines at the airport.
\end{abstract}

Keywords: Airlines, Brazil, Flight Disruptions, ANAC 400 resolution, automated disruption assistance (ADA), prototype

\section{INTRODUCTION}

In Brazil, commercial aviation is a sector where margins are relatively low and highly exposed to externalities. Since the apparition of GOL in 2001 as the first low-cost carrier (LCC), the concern for cost reduction increased. The aviation industry started many initiatives, such as firming agreements between different airlines to ease misconnections solutions or the implementation of a flight slot management model to minimize delays and cancellations. Miranda and Oliveira (2018) created an econometric model to demonstrate how the different strategies of slot management impact the costs of the airlines in case of flight disruptions.

All airlines that operate in Brazil must strictly comply with Resolution 400 of Agência Nacional de Aviação Civil (ANAC). It requires the airlines to provide a certain level of material assistance to customers that vary according to the severity and the duration of the disruption.

Disruptions represent one of the most significant expenses of an airline, and as the handling of these situations is highly regulated, there is only little room for cost reduction. During a disruption, time becomes a critical dimension. The challenge for the airline is to recover as soon as possible. There is still a high volume of manual processes to execute. This process requires a significant number of employees to deal appropriately with re-accommodation, voucher issuance for meals and hotels, and the other services stated by the Regulation. For the last years in Brazil, the researchers couldn't see significant changes in the way of handling disruption that provides cost reduction.

The purpose of this study is to design a solution that reduces the cost of the Headcount of the company. The researchers will provide a self-service solution to customers that allows them to choose their re-accommodated flight and issue their vouchers. The automated disruption assistance (ADA) concentrates on the integration between the airlines and hotel, transport, and meal providers to facilitate the re-accommodation logistic for the passengers affected by the disruption. The solution aims to provide these services to the passenger through the mobile application (APP) of the company. In other words, the solution intends to bring more efficiency to the operation and savings for the airline from a financial perspective. This study will improve disruption handling and demonstrate the unnecessary spending of money in manual processes that are not easily auditable and susceptible to human failures.

Even in 2019, flight disruptions are still a problem for airlines. In the next sections, the researchers will go deeper through the improvements that appeared in the last years regarding the processes related to disruption management. 


\section{REGULATIONS IN BRAZILIAN AND EUROPEAN MARKETS}

In an industry where cost control is essential to achieve positive financial margins, companies need to keep looking for better processes that reduce consumption of time and, consequently, expenses. The contingency costs in the daily operations of the airline are caused by numerous factors such as adverse weather, unscheduled aircraft maintenance, or airport security, among others.

In Brazil, the airlines are required to provide material assistance to any passenger who is affected by a flight delay or cancellation, and these obligations may vary according to the impact on the passenger. In case of non-compliance with the regulations, the company may receive a fine of a minimum of $R \$ 20,000$ and a maximum of $R \$ 50,000$ per passenger affected.

Another market that presents some similarities from the Brazilian is the European market, where terms of material assistance are guaranteed by the European Commission (EC) document 261/2004. This document specifies in detail the responsibilities of airlines regarding delays, cancellations, and overbooking. There is a significant contrast with the US market, regulated by the Department of Transportation (DOT). In the USA, the airline cannot be held responsible for schedule changes and cancellations and require the airlines to provide material assistance only in case of overbooking.

\section{Resolution 400 of the Brazilian National Civil Aviation Agency (ANAC)}

According to resolution 400, material assistance is to meet the needs of the passenger. The airline should provide it free of charge depending on the waiting time even if passengers are on board the aircraft with its doors open as follows:1) more than 1 (one) hour: communication assistance; 2) more than 2 (two) hours: meals, according to the schedule, by providing meals or individual voucher; and 3) more than 4 (four) hours: overnight accommodation service and round-trip transfer. The carrier may cease to offer accommodation service to the passenger residing at the local airport of origin, guaranteed the round-trip transfer. The re-accommodation will be free of charge, will not override the transport contracts already signed. Moreover, it will take precedence over the conclusion of new transport contracts, and should be made, at the choice of the passenger, as follows: 1) on own or third-party flights to the same destination at the earliest opportunity; or 2) on the carrier's flight to be performed on the date and time of the convenience of the passenger.

\section{Interpretative Guidelines on Regulation (EC) No 261/2004 of the European Parliament}

The Regulation protects passengers against denied boarding, cancellation, delay, upgrading, and downgrading. These events, as well as the rights granted to passengers when they materialize, are described in the sections below. Passengers whose flights are canceled should be able to obtain reimbursement of their tickets or rebooked and adequately cared for while awaiting a later flight. The Montreal Convention, adopted by the International Civil Aviation Organization (ICAO) in 1999, was ratified by Brazil in 2006. All obligations on operating airlines should be limited or excluded in cases where extraordinary political instability, meteorological conditions incompatible with the operation of the flight concerned, security risks, unexpected flight safety shortcomings, and strikes that affect the process of an operating air carrier circumstances that have caused an event. In other words, cases that could not have been avoided even if airlines take all reasonable measures. Such circumstances may, in particular, occur in cases when an operating air carrier reasonably expects a flight to be delayed beyond its scheduled time of departure: a) for two hours or more in the case of flights of 1500 kilometers or less it is necessary to provide meals and refreshments in a reasonable relation to the waiting time; (b) for three hours or more in the case of all intra-Community flights of more than 1500 kilometers and all other flights between 1500 and 3500 kilometers; it is necessary to provide meals and 
refreshments in a reasonable relation to the waiting time and hotel accommodation with transport between the airport and hotel.

\section{Impact of Disruptions and Strategies for Recovery}

The analysis of the Brazilian and European regulations demonstrates that the cost of disruption is a real offender for the airline's profits. Through our review of the literature, the researchers found some studies that proposed different strategies for disruption recovery.

Jafari and Zegordi (2011) pointed out the impact of a disruption on the aircraft operation, crew, and, of course, passengers. However, other aspects need to be taken into consideration when an airline looks at disruption management. Ground staff, gate, and catering are resources that play an essential role in the management of a disruption. Most of the published studies that the researchers cite a focus on aircraft recovery, schedule recovery, and techniques to mitigate the costs of airline disruption. Clausen et al. (2010) highlighted how aviation is one of the industries that took advantage of Operation Research (OR) for the past years. They proposed an integrated research method of disruption management by robustness. This method uses a buffer in the airline schedule to make flight and crew schedules as well as aircraft rotation less sensitive to disruption.

Maher (2015) recognizes that passenger recovery is usually the last step of a flight disruption recovery process and that the related costs significantly affect operational efficiency. In his study, he uses OR to create a model that enhances passengers flow and minimize costs, in case of flight cancellation decision.

However, from a passenger perspective, there are a lot of possibilities for the airlines to improve the processes to passenger assistance with accommodation and compensations. Lettovsky (1997) states that passengers may understand that the airline is not responsible for the bad weather and the cancellation of a flight is due to safety reasons. On the other hand, in cases where the passengers cannot see the problem or cancelation reason, they will hardly understand that it would affect the entire network. This situation usually frustrates the passenger, leading to the loss of future revenue for the airline. In terms of flight cancellation costs, Lettovsky (1997) also showed in his study the importance of considering costs of reassigning passengers, hotels, and meals, as well as an estimation of the loss of passenger goodwill. Bratu and Barnhart (2006) developed a model that focused on finding a balance between the cost of operation of an airline and the cost generated by passenger delay. It additionally highlights the importance of customer satisfaction in the mean that it affects their loyalty and consequently affect the revenue of the airlines.

Cook et al. (2009) developed a decision-support tool for managing flight delay costs in the pre-departure and airborne phases of a flight. They determined that expenses related to passengers are comprised of different aspects. Examples include re-accommodation and compensation (hard costs are borne), loss of market share due to passenger dissatisfaction (soft costs are borne), and cost borne by the passenger like the impact of late arrival at a meeting.

\section{The Current Process}

The Brazilian airline's current process is extremely manual and has a low level of governance due to its fragility. The manual steps are presented in figure 1.

Mostly, when there is a delay or a flight change time of more than 2 hours, passengers are called and sorted by airline employees. After this process, the airline provides a new itinerary and the required vouchers to attend the National Civil Aviation Resolution 400. The airport agents of the airline execute this process.

In case of a flight delay greater than 2 hours and lesser than 4 hours, the passengers are qualified to receive meal vouchers. For flight delay greater than 4 hours, additionally, the passengers are entitled to hotel accommodation and transportation from the airport to the hotel.

Based on this scenario, there is an excellent opportunity for process optimization and governance improvements through automation. According to Kurian (2013), the business process reengineering is performed in 3 phases: (1) 
process capture and business modeling, (2) process redesign, and (3) process support. In figure 1 below, the researchers mapped the current process run by the Brazilian airlines.

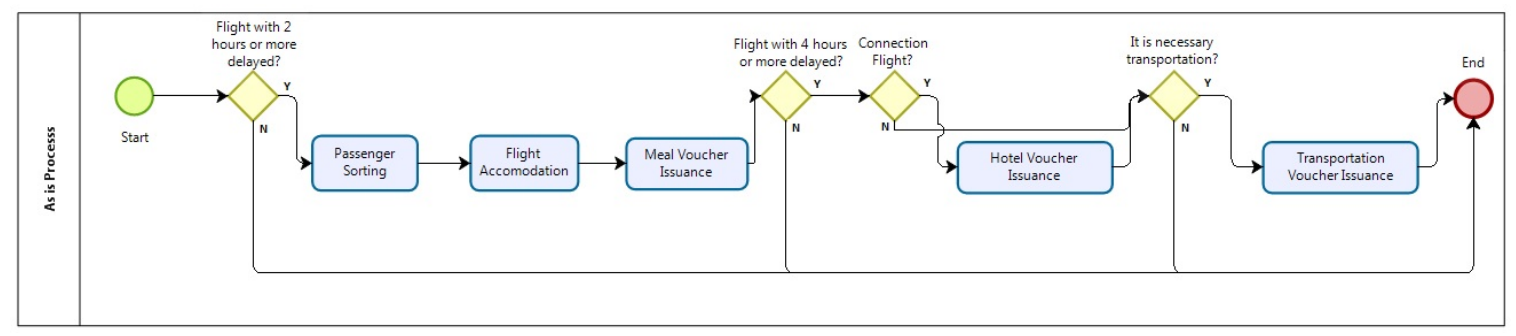

Figure 1. The Current Process of Passenger Treatment Under ANAC 400 Resolution

\section{Self-Service Solutions}

The air transport industry globally embraced the creation of self-service solutions for its customers. The International Air Transport Association (IATA) created a program named Fast Travel that concentrates on offering more options to the customers and lowering the cost for the industry. The program focuses on six key areas, and flight rebooking is one of these areas. The IATA estimates that the saving represented by the self-service options in the six regions represents a saving of 2.1 billion US dollars annually for the industry.

Protus and Govender (2016) suggest that even if some self-service solution may impact negatively in comparison to person-to-person interactions, the customers appreciate the reliability and the time saving provided by self-service solutions. Another advantage of a self-service solution is the avoidance of long queues at the airport, especially at peak hours. This item is relevant in the overall customer experience with the airlines. However, to maximize customer satisfaction, it is mandatory that these solution's reliability is high and to provide efficient contingencies in case of problems with the technology. Otherwise, the effect on customer satisfaction can be dramatic.

\section{METHODOLOGY}

The researchers used some descriptive measures to understand what opportunities are found in the current process for material assistance. They used four data sets extracted: Historical data for delays and cancellations flights, Missed connection rate, Material assistance cost, and Headcount and cost.

To identify and analyze the critical data, the researchers considered the following variables: Total number of operated flights per airline, the total number of delayed and canceled flights, Total number of passengers transported per airline, Average flight occupancy per airline, percentage of passengers connecting, percentage of the missed connection, and the average cost of an employee. The number of flights and passengers were collected considering the years 2017 and 2018. Table 1 reflects the estimated time spent by Brazilian airlines in rebooking and material assistance processes, according to the requirements of ANAC resolution 400. The time process was provided by airlines according to the current scenario.

Table 1. Time Process Per Passenger and Action

\begin{tabular}{|l|l|l|l|l|}
\cline { 2 - 5 } \multicolumn{4}{c|}{} & \multicolumn{4}{l|}{ Time process per passenger } \\
\cline { 2 - 6 } \multicolumn{1}{l|}{} & $40 \mathrm{sec}$ & $40 \mathrm{sec}$ & $40 \mathrm{sec}$ & $3 \mathrm{~min}$ \\
\hline $\begin{array}{l}\text { Missed } \\
\text { Connections }\end{array}$ & Yebooking & Meals & Transport & Hotel \\
\hline $\begin{array}{l}\text { Canceled } \\
\text { Flights }\end{array}$ & Yes & $\begin{array}{l}\text { According to } \\
\text { accommodation }\end{array}$ & $\begin{array}{l}\text { According to } \\
\text { accommodation } \\
\text { accommodation to }\end{array}$ & $\begin{array}{l}\text { According to } \\
\text { accommodation }\end{array}$ \\
\hline$>$ ach Delays & No & Yes & No & $\begin{array}{l}\text { According to } \\
\text { accommodation }\end{array}$ \\
\hline$>$ 4h Delays & No & Yes & Yes & No \\
\hline
\end{tabular}


On missed connections and canceled flights scenario, the rebooking process can variate according to the next flights available. Currently, employees responsible for the rebooking process and for providing material assistance vouchers, work in the back-office (BO) area. The solution aims to provide a reduction in manual interaction and, consequently, to reduce the number of employees required in this sector. According to Brazilian airlines, back-office employees represent $10 \%$ of the total station's Headcount. To understand the total cost of employees in Brazil; the researchers considered the formula below:

Cost per Headcount= Salary+Taxes

\section{Simulation of the As-Is and To-be process}

To demonstrate the feasibility and efficiency of the new process involving the accommodation and voucher issuance, this study also aims to simulate the As-Is process (Fig.1) and To-Be process containing all proposed automation and changes.

\section{The To-be Process}

The new process is designed to automate the current process and provides greater governance and traceability of issued vouchers the to-be process has similar steps to the ongoing process. However, it brings a high level of automation in each of the planned actions that make it simpler and more agile. It also logs information into a database that helps controlling costs related to legal obligations provided. This new process proposal consists basically of 8 steps, such as System Input, Passenger Sorting, Flight Re-Accommodation, Meal Voucher, Hotel Voucher, Transportation Voucher, Voucher provision, and Data Storage for future analysis. This process is highlighted in Figure 2.

1. System input: When a flight is delayed by 2 hours or more, an airline employee must enter this information on Automated Digital Assistance (ADA). Then the tool starts the entire automated management process. The company employee may be assigned to the airport staff or operations control center.

2. Passenger Sorting: Even with the automation of the process, there will be at this stage sorting of the passengers by destination and prioritization according to the customer's tier level in the airline frequent flyer program.

3. Flight Re-Accommodation: At this stage of the process, the customers will be accommodated to a new flight according to the priority set in the previous step so that the frequent flyer will have a preference for the best accommodations.

4. Meal voucher: As per customer rights, he/she will receive a meal voucher, and this voucher will be valid until the departure time of his/her new flight.

5. Hotel voucher: In the fifth phase of the process, only passengers in connection receive a hotel voucher if the delay or change of the flight departure has more than 4 hours of difference from the original departure time. It is noteworthy that for this voucher issuance, the prioritization defined in step 2 will be considered, providing earlier assistance to frequent passengers.

6. Transportation voucher: The transportation voucher is provided to passengers who have received a hotel voucher. But only when the selected hotel does not offer a shuttle service and also to local passengers who may wish to return home.

7. Voucher provision: This is the final phase of the process that directly involves the passenger. At this moment, a push notification will appear on his/her mobile phone through the airline APP, making available the vouchers that are the obligation of the company and customer rights.

8. Data Storage: The last part of the process is the storage of all affected passenger and voucher data that can be used for future analysis for continuous improvement, cost control, and auditing purposes.

It is essential to mention that this whole process assumes that the passenger has installed the airline APP on his/her mobile phone. However, in cases where the passenger does not have installed the APP, he/she can obtain the vouchers from a company employee that can print it through the disruption management module control screen. 


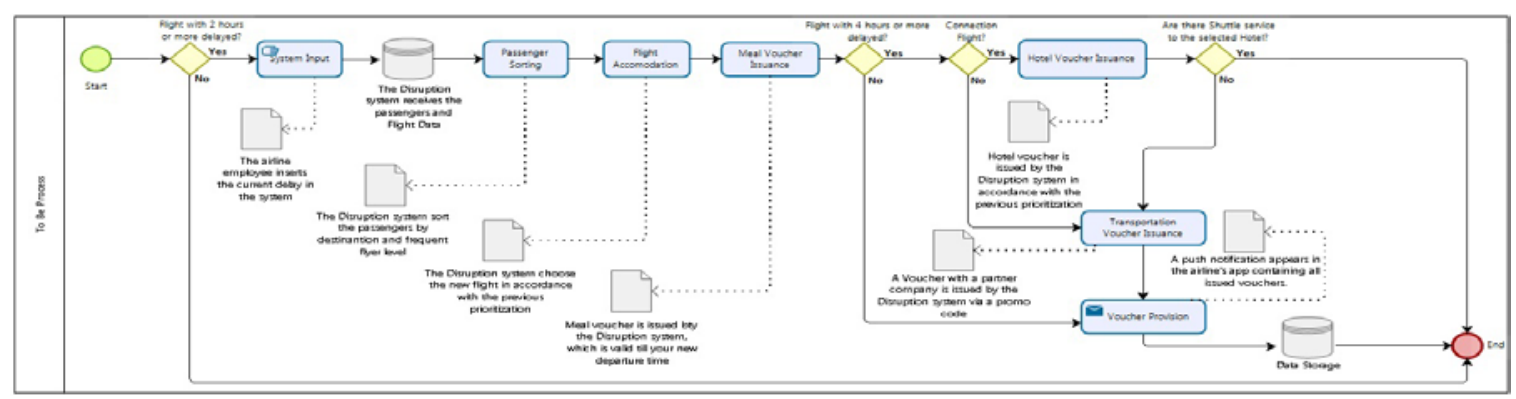

Figure 2. The To-Be Process of Passenger Treatment Under ANAC 400 Resolution

\section{OUTCOMES}

After collecting operational data from the three major airlines in Brazil, it was possible to analyze and work with some disruption scenarios. All results presented in this study were focused on hub airports, which have a large volume of transported connections and flights. In other words, the Hub and spoke model. The main scenarios analyzed were:

- Missed connections

- Canceled Flights

At the request of airlines, all data will be presented with the code name A, B, and C, to keep the information available confidential. To begin the study, the researchers consolidated the information on flights and passengers carried in 2017 and 2018, as presented in Tables 2 and 3.

Table 2. Total of Carried Passengers in 2017 and 2018

\begin{tabular}{ccc}
\hline \multicolumn{3}{c}{ Carried Passengers } \\
Airline & 2017 & 2018 \\
\hline A & $32.300 .413,00$ & $33.394 .299,00$ \\
B & $33.548 .185,00$ & $34.114 .685,00$ \\
C & $21.476 .344,00$ & $22.557 .925,00$ \\
\hline Total & $87.324 .942,00$ & $90.066 .909,00$ \\
Average & $29.108 .314,00$ & $30.022 .303,00$ \\
\hline
\end{tabular}

Table 3. Total of Flights Operated and Canceled Flights in 2017 and 2018

Flights in 2017

Flights in 2018

\begin{tabular}{ccccc} 
Airline & Operated & Canceled & Operated & Canceled \\
\hline A & $242.720,00$ & $1.362,00$ & $250.924,00$ & $1.593,00$ \\
B & $232.723,00$ & $2.460,00$ & $245.627,00$ & $2.310,00$ \\
C & $241.153,00$ & $3.073,00$ & $257.440,00$ & $3.998,00$ \\
\hline Total & $716.596,00$ & $6.895,00$ & $753.991,00$ & $7.901,00$ \\
Average & $238.865,33$ & $2.298,33$ & $251.330,33$ & $2.633,67$ \\
\hline
\end{tabular}

When the researchers asked airlines about the percentage of connections carried in flights and the percentage of missed connections, data were presented from a macro perspective for strategic market reasons.

- Percentage of connections in hubs: $37 \%$

- Percentage of missed connections in hubs: $2 \%$ 


\section{Minimum wage}

According to SNEA's collective agreement 2018/2019, the minimum wage of an employee who acts as an airport agent is $\mathrm{R} \$ 1332.83$. Assuming that employee's rates in Brazil are approximately $70 \%$ of the salary paid, the researchers consider the formula below for cost per Headcount.

Cost per Headcount $=1332.83+70 \%$ Salary $=\mathrm{R} \$ 2265.81$

\section{Scenarios}

Scenario A - Missed Connections

To begin the scenario design, the researchers considered the volume of flights and passengers carried in 2018, due to the continuous growth of the Brazilian aviation market. Analyzing the data collected, the number of operated flights increased by 5\% from 2017 to 2018. Table 4 highlight Scenario A Rational

Table 4. Scenario A Rational

\begin{tabular}{|c|c|c|}
\hline Description & Qty & Logic \\
\hline Average passengers carried per year & 30022303 & Passenger carried per airline \\
\hline Passengers with connection per year & 11108252 & $* 0.37$ \\
\hline Missed connection per year & 222165 & *0.02 \\
\hline Missed connection per day & 609 & /365 \\
\hline Missed connection per day in each Hub & 152 & /4 (assuming four hubs per company) \\
\hline Time spent (minutes) & 761 & $\begin{array}{l}\text { * } 5 \text { min - Considering } 5 \text { minutes (rebooking } \\
\text { and all material assistance service) }\end{array}$ \\
\hline Passengers served/hour & 12 & $\begin{array}{l}\text { Affected passengers day hub * } 60 \text { / time spent } \\
\text { (minutes) }\end{array}$ \\
\hline Required hours & 13 & / 60 (change from minutes to hours) \\
\hline Required agents (working per hub) & 2 & / 6h (airport agent workday) \\
\hline Required agents (minimum of 1 per shift) & 4 & Four shifts of 6 hours each one \\
\hline Required agents (total per hub) & 5 & $+30 \%$ scale factor \\
\hline Required agents in the airline & 21 & $* 4$ hub \\
\hline Agent Salary + taxes & $2.265,81$ & Cost per Headcount \\
\hline Total cost in all Hubs per month & $\mathrm{R} \$ \quad 47.128,87$ & $\begin{array}{l}\text { Required agents in the airline } * \text { (Salary }+ \\
\text { taxes) }\end{array}$ \\
\hline Total cost in all Hubs per year & $\mathrm{R} \$ 565.546,43$ & Total cost in all Hubs per month * 12 \\
\hline
\end{tabular}

According to the logic presented, an airline that has the operation with the characteristics described in this scenario can save $\mathrm{R} \$ 565.546,43$ per year automating its disruption processes.

\section{Scenario B - Canceled flights}

Scenario B was designed based on the number of cancellations and average load factors of 2018 of the three main airlines in the Brazilian market. Scenario B considered that only the provision of meal and transport vouchers was required. Based on data released by the airlines, about $38 \%$ of cancellations are from flights that have its departure from any hub. And it was possible to reach the average number of flights canceled per day on these stations. In Table 5 , we can see the average annual load per flight and airline. 
Table 5. Average Annual Load per Flight and per Airline

\begin{tabular}{ccc}
\hline Airline & 2017 & 2018 \\
\hline A & 133 & 133 \\
B & 144 & 139 \\
C & 88 & 87 \\
Average & 122 & 120 \\
\hline
\end{tabular}

Finally, with this data, it was possible to develop a rational to reach the necessary number of agents for this function. And also, to estimate the potential saving since the process automation will replace this need.

Table 6. Scenario B Rational

\begin{tabular}{|c|c|c|}
\hline Description & Qty & Logic \\
\hline Canceled flight per day in hubs & 1,66 & According to the database collected \\
\hline Average Load Factor per flight & 120 & According to the database collected \\
\hline Time spent (minutes) & 398 & $\begin{array}{l}\text { * } 2 \text { min - Considering } 2 \text { minutes per pax (rebooking, meal and } \\
\text { transport) }\end{array}$ \\
\hline Required hours & 7 & / 60 (change from minutes to hours) \\
\hline Required agents (working per Hub) & 1,11 & / 6h (airport agent workday) or the minimum of 1 agent \\
\hline Required agents (total per hub) & 1,44 & $+30 \%$ scale factor \\
\hline Required agents in the airline & 6 & * 4 hubs \\
\hline Agent Salary + taxes & $2.265,81$ & Cost per Headcount \\
\hline Total cost in all Hubs per month & $\mathrm{R} \$ \quad 13.038,99$ & Required agents in the airline $*($ Salary + taxes $)$ \\
\hline Total cost in all Hubs per year & $\mathrm{R} \$ 156.467,84$ & Total cost in all Hubs per month * 12 \\
\hline
\end{tabular}

For this scenario, the researchers selected the lowest daily cancellation rate among the three airlines.

\section{Savings Scenario A and B}

Scenarios A and B happen simultaneously, causing missed connections due to flight delay and flight cancellation, respectively. So, the expected annual maximum potential saving should remain under R 565.546,43.

The potential saving mentioned can be achieved through the reduction of Headcount and the new automated process.

\section{As-Is and To-Be Process Efficiency Comparison}

1. As-Is process: The current process with all the manual tasks involved and their specific duration requires at least 17 employees hired to the airline, leading to a high annual cost.

2. To-be Process: The new process brings a significant gain in efficiency. The execution time of issuance and delivery of vouchers takes about 2 minutes for all affected passengers of the flight. Considering that the current process can take up to 5 minutes per passenger, the gain is significant. Also, there is no need for dedicated agents for the passenger accommodation process. 
This new process will eliminate the headcount profile required for the activity. The only Headcount needed in the new process is already present in other company activities, whether at the Operation Control Center (OCC) or the boarding gate.

\section{Arena Simulation}

Arena is a simulation software developed by Rockwell Automation that helps to understand the potential impact of a specific business process decisions before they are implemented. The simulation of the current and new processes through Arena models allowed us to change and test alternatives to determine the best in terms of efficiency. The researchers considered elements as a contribution to the mitigation of the risk of failures, identification of possible bottlenecks, and reduction of idle time.

\section{Simulation Process As-Is}

Considering the data of scenarios A and B previously mentioned in the study, the researchers simulated the current process for 30 days at one Hub.

During the simulations, the researchers made several changes trying to concentrate the assistance in two or three shifts. But the researchers realized that the maximum waiting time for rebooking and issuing vouchers of each passenger correspond to the moment where no agent is working at the customer service.

After replicating the simulation, the researchers identified that the result pointed out that at least one employee must permanently be available. It also showed that a shift reduction caused a waiting time of 6 hours. Refer to Figures 3 and 4.

\begin{tabular}{|c|c|c|c|c|c|c|c|}
\hline Replications: & Tirre Units & Minute & & & & & \\
\hline \multicolumn{8}{|l|}{ Time } \\
\hline Waiting Time & & Aversoge & Half Width & $\begin{array}{c}\text { Minimum } \\
\text { Aversage }\end{array}$ & $\begin{array}{c}\text { Maximum } \\
\text { Average }\end{array}$ & $\begin{array}{c}\text { Minimum } \\
\text { Value }\end{array}$ & $\begin{array}{c}\text { Maximum } \\
\text { Value }\end{array}$ \\
\hline Rebooking and & oucher.Queue & 2.8398 & 0,33 & 1.5263 & 5.7545 & 0.00 & 38.3750 \\
\hline
\end{tabular}

Figure 3. Simulation Including Four Shifts

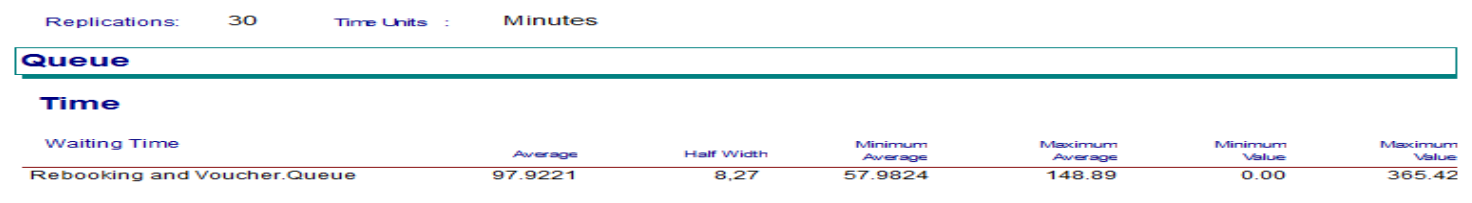

Figure 4. Simulation Including Three Shifts

\section{To-Be Process Simulation}

With the simulation of the to-be process, it became clear that there is still a need for human intervention to start the automated process. However, this process only takes a few seconds to execute. It can be assigned to an employee located at the company's OCC, which is already responsible for monitoring passengers who have connecting flights. Thus, it ensures the gain by reducing the number of people involved in the manual process of issuing and delivering vouchers. 
On the new solution, the waiting time became insignificant because it only relies on the action of the passenger in the APP. The process full process is executed by the passengers and can be performed simultaneously by all the impacted passengers.

\section{Technical Solution Design}

The automation of the process requires the construction of an IT solution, integrated with the Passenger Service System (PSS) of the airline, and implemented in the airline's APP. A PSS is the central system of an airline. It allows the company to manage the network, the pricing, the inventory, and sales. It also allows the airline to execute the check-in and boarding processes of the passengers.

The integration with the PSS is necessary to get the information of the available flights in case of re-accommodation and move the passengers from a trip to another flight. The integration will be made through an Application Programming Interface (API), available in the PSS used in Brazil: Sabre Sonic, Amadeus Altea and Navitaire NewSkies.

The core of the solution is comprised of:

- a set of business services,

- a configuration module that allows the parameterization of business rules to apply,

- a reporting interface to generate a relevant report regarding vouchers issuance,

- an Online Transaction Processing (OLTP) database to store all the transactions executed by the solution,

- an Online Analytical Processing database to store information for reporting,

- a configuration database to store all the parameters values set through the configuration user interface,

- an API to allow the APP consuming the business services,

- a service that generates data feed for the revenue accounting system.

Besides the integration with the PSS API, the solution will integrate with Uber's API to issue a transport voucher. For hotel voucher issuance, the solution will also need to integrate with partners API. The partners can be different from one airline to another, so the number of integrations can vary by the number of partners.

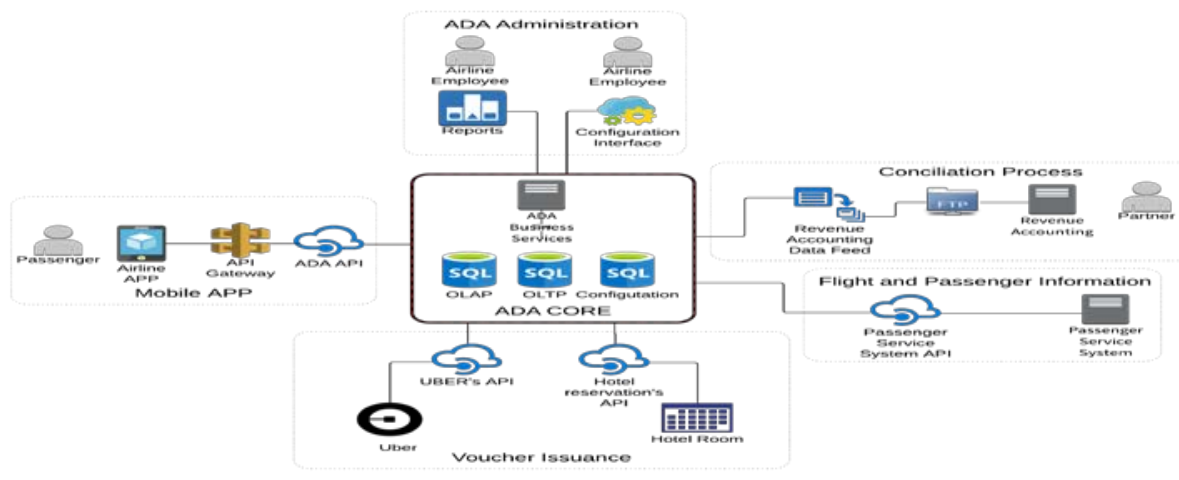

Figure 5. The architecture of the IT Solution 


\section{IMPLEMENTATION}

The researchers estimated the timeframe of the solution's implementation in six months. It encompasses the effort of development of the core solution, all the integrations with third parties, and the development of the airline's APP.

The training of the carrier's personnel can happen before the final version is ready, using the version available for User Acceptance Test (UAT). As the solution is integrated with the airline's APP and the interaction with the passenger is triggered by a disruption event, there is no need for a particular previous communication with the passengers that already installed the APP on their mobile. Therefore, the availability of such self-service functionality represents an absolute competitive advantage for the airlines, so the researchers recommend that the airline mention the service in their current or future marketing campaigns related to their APP to incentive its usage.

\section{Prototype}

A prototype was designed to simulate how the solution works from both airline and customer perspectives. The screens detailed here represent the scenario where the airline canceled a flight, and the airline agent needs to propose a new flight option to the customer so that the customer can reach his/her final destination. The second flow represents the customer affected by this event, which received a push notification in his mobile app alerting about the flight cancellation. After that, the customer proceeds with the flight change process and get the vouchers (material assistance) according to the ANAC 400 Resolution. Refer to figures 6 to 9.

\section{Airport Disruption Back-Office Portal}

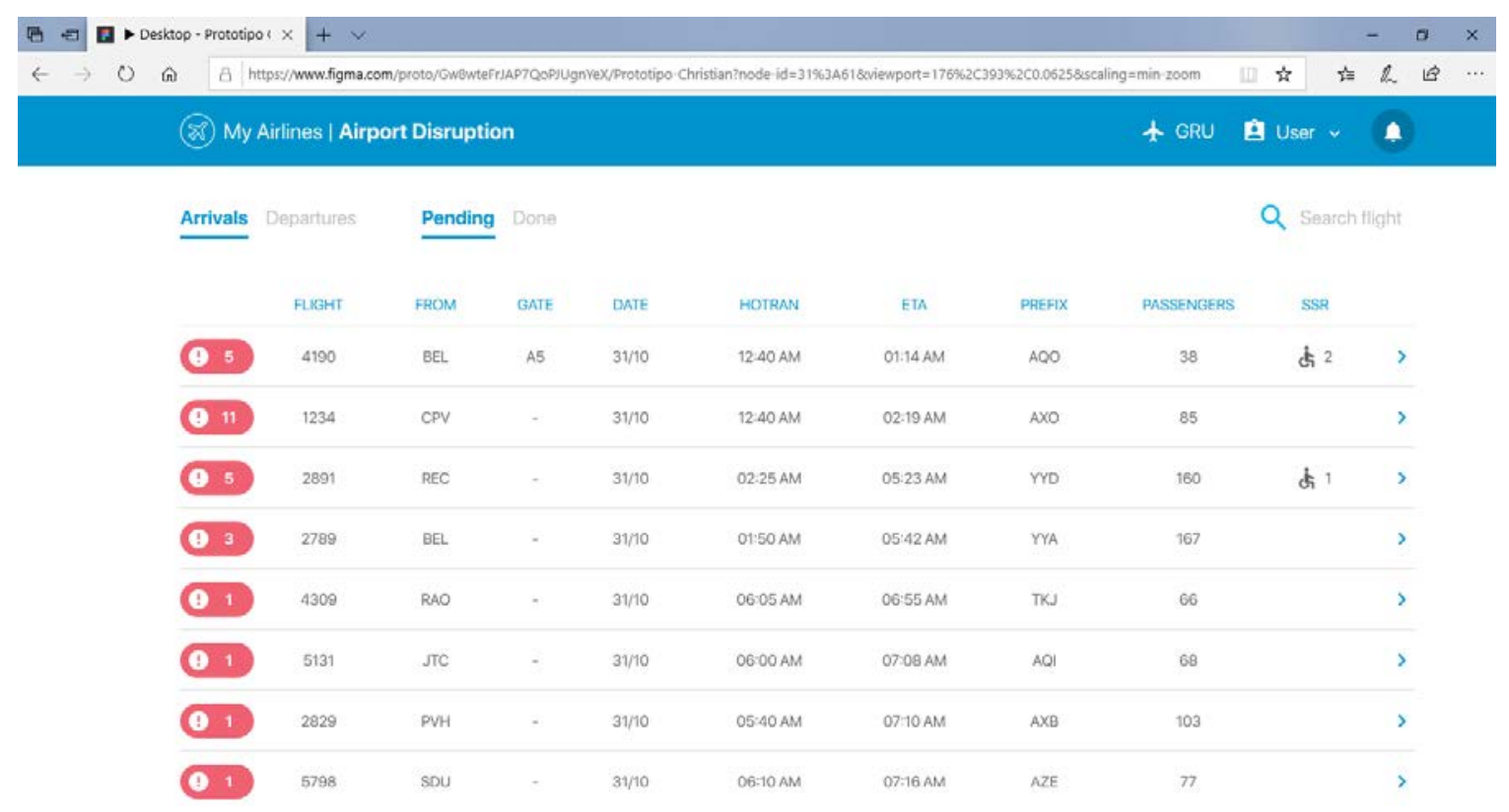

Figure 6. Airline Back-Office Portal Prototype

Figure 6 lists the Flights Canceled or Delayed with the Number of Passengers Affected Who Need to be Assisted. 


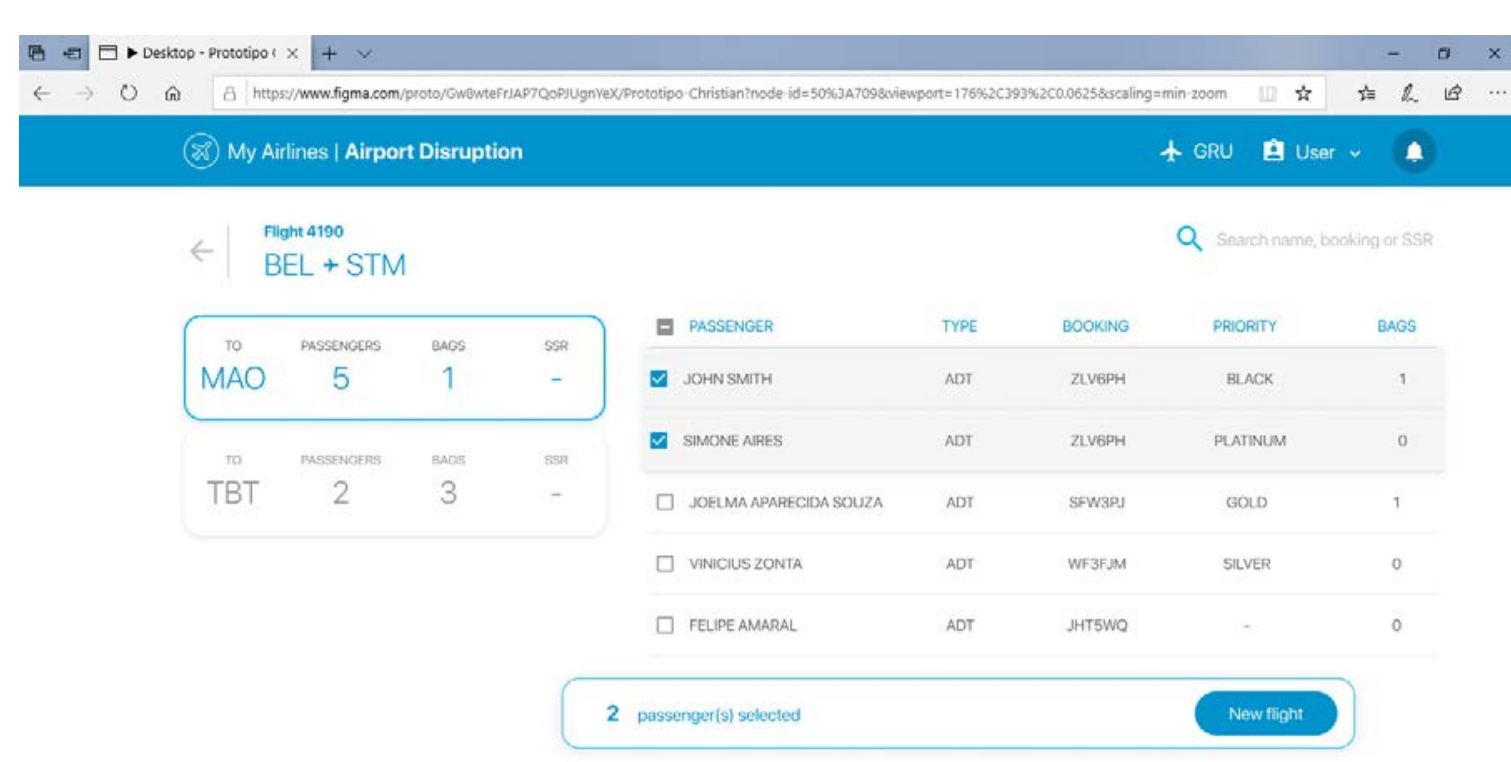

Figure 7. Airline Back-Office Portal Prototype - Customers List Affected by the Flight Disruption Event

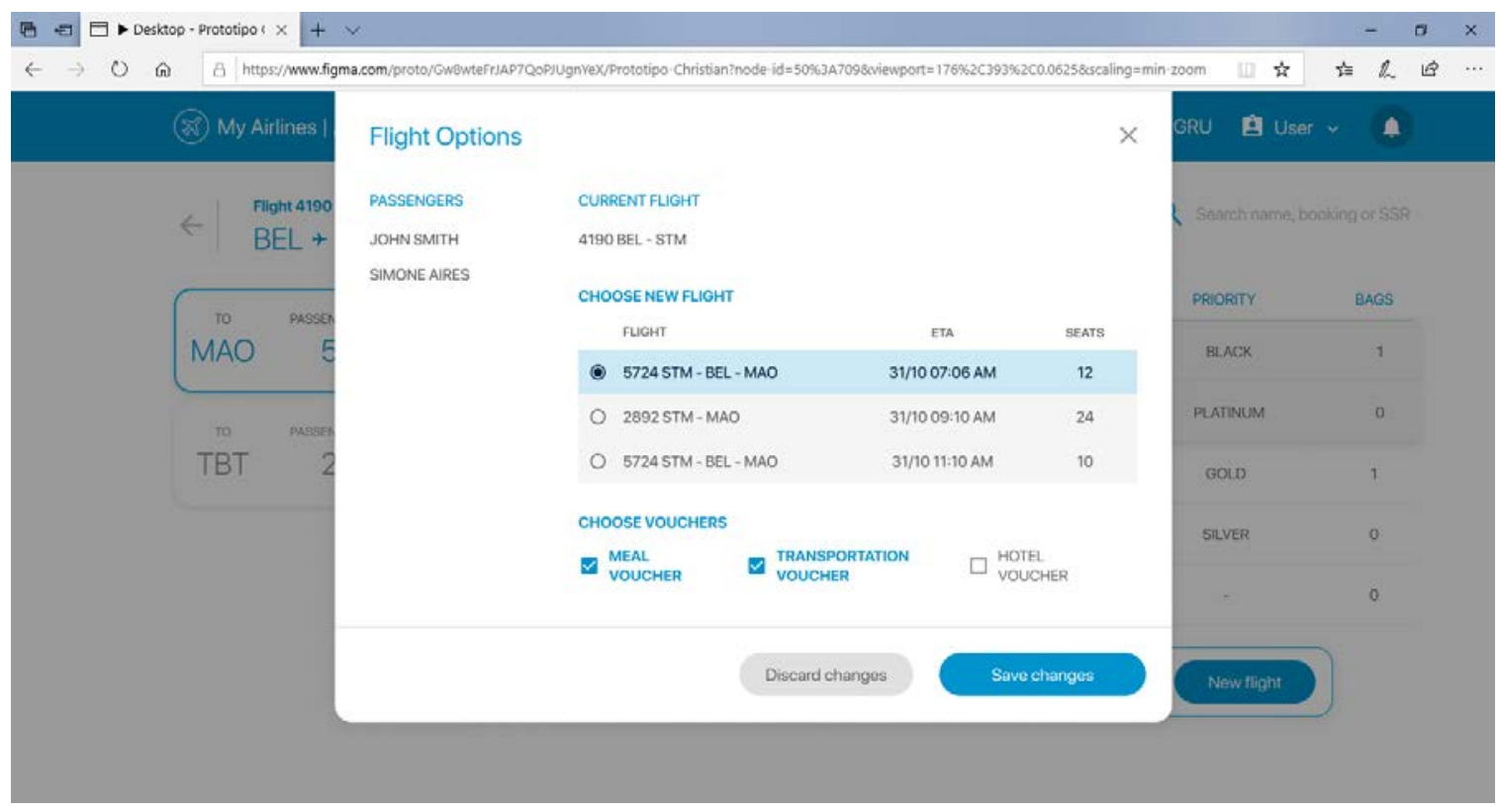

Figure 8. Airline Back-Office Portal Prototype - Flight Options Available for the Flight Change and the Vouchers Options to be Issued 


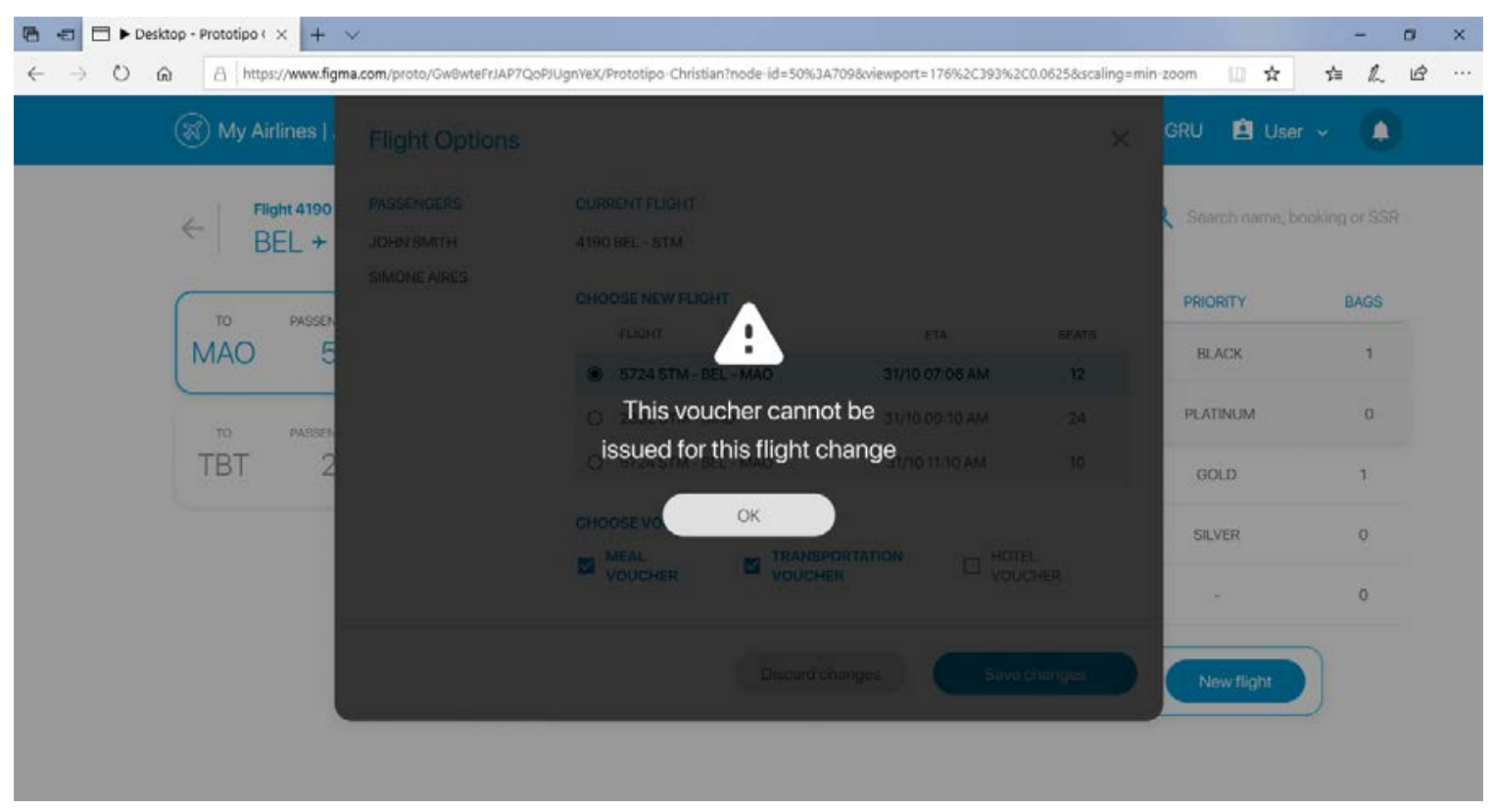

Figure 9. Airline Back-Office Portal Prototype - System Validation for the Vouchers Issuance

\section{CONCLUSIONS AND RECOMMENDATIONS}

Surely, ANAC resolution 400 in Brazil represents an additional operational challenge for Brazilian airlines. Delays or cancellations bring consequences for airline operations. Also, companies need to be agile to minimize impacts on passenger experience, especially when it comes to material assistance, such as meals, transport, and hotel. However, within this challenge, the researchers identified that there are opportunities to turn the process more efficient.

Mobility is one of the critical points in this process. The use of devices in customer service drives productivity through interaction with agility, allowing customers to move on their journey without employee's interference or facing long queues at the airport.

By automating processes, airlines will have the opportunity to optimize the ground staff headcount, enabling customers to obtain material assistance according to resolution 400. The purpose of this study was to develop a solution that brings cost savings to airlines as wells as to provide passengers with a seamless and smooth experience.

According to our analysis, the ADA project brings R\$ 427.288,95 of saving in two years and an annual saving of R\$ 476.231,08 after the first year. The developing cost is estimated at $\mathrm{R} \$ 242.400$, which means that the payback will be lesser than 24 months. Besides the project being paid, ADA will bring more reliability to the process and will generate a complete database for disruption cases.

ADA brings an innovative solution that aims to identify and bring agility in solving the problems that can occur, generating intelligent solutions for rebooking and material assistance. The tool focuses on allowing customers to choose the services according to their preferences.

\section{RECOMMENDATIONS}

Besides the scenarios explored in this study, there are other scenarios with opportunities to be explored in future research. Due to information limitations provided by airlines, the researchers recommend further studies be conducted to reinforce the tool's gains. There is a vast number of customers with connections flights that are affected by short 
delays from ten minutes to one hour. Depending on the rebooked flight, material assistance may be required. For this study, the researchers considered the tool being used through smartphones or tablets. Other scenarios could also be explored through kiosks.

Investments in creating customer-centric oriented by digital experiences can facilitate the engagement of current and new costumers. It also can contribute to increasing long-term brand loyalty. Airlines need to find solutions to strengthen ties and keep costumers engaged using technology as a part of the process. Regardless of the mode and how the interaction with customers happens, the customer journey needs to be consistent and positive.

The solution proposed here gives the airline the possibility of tracking all the costs associated with the material assistance with customers. It also brings the benefit of auditing control. However, it is recommended to define an entity in the airline's organization that will be responsible for extracting, analyzing, and managing all information provided by the platform. The continuous improvement of the processes depends on the engagement of the team and the focus the airline will give to the subject.

Finally, the researchers recommend studying the variation in the cost of voucher issuance. As the redemption of vouchers is more comfortable with the self-service solution, the number of redeemed vouchers might increase after the implementation of the solution. Therefore, the corresponding cost increase might be compensated with a cost reduction due to a lower number of passengers suing airlines due to the absence of material assistance.

\section{KEY LESSONS LEARNED}

The limitation of information regarding the airline's rebooking reports was a barrier to measuring other potential gains. ANAC should request this data from airlines to ensure compliance with 400 resolution, in addition to having a centralized database. Also, airlines would ensure resolution compliance by reports, according to the rebooking and material assistance provided.

\section{REFERENCES}

Bratu, S., \& Barnhart, C. (2006). Flight operations recovery: New approaches considering passenger recovery. Journal of Scheduling, 9(3), 279-298. doi:10.1007/s10951-006-6781-0

Clausen, J., Larsen, A., Larsen, J., \& Rezanova, N. J. (2010). Disruption management in the airline industryConcepts, models and methods. Computers and Operations Research, 37(5), 809-821. doi:10.1016/j.cor.2009.03.027

Cook, A., Tanner, G., Williams, V., \& Meise, G. (2009). Dynamic cost indexing - managing airline delay costs. Journal of Air Transport Management, 15(1), 26-35. doi:10.1016/j.jairtraman.2008.07.001

Fodness, D., \& Murray, B. (2007). Passengers' expectations of airport service quality. Journal of Services Marketing, 21(7), 492-506.

IATA. (2019). Fast Travel Program. Retrieved from https://www.iata.org/whatwedo/passenger/fasttravel/Pages/index.aspx

Process mapping. (2013). In G. T. Kurian, The AMA dictionary of business and management. New York, NY: AMACOM, Publishing Division of the American Management Association. Retrieved from http://ezproxy.libproxy.db.erau.edu/login?url=https://search.credoreference.com/content/entry/amadictbm/p rocess_mapping/0?institutionId $=951$

Lettovsky, L. Airline operations recovery: an optimization approach [Ph.D. thesis]. Georgia Institute of Technology. 1997.

Maher, S. J. (2015). A novel passenger recovery approach for the integrated airline recovery problem. Computers and Operations Research, 57, 123-137. doi:10.1016/j.cor.2014.11.005 
Maruster, L., van Beest, N. R., T, \&, P. (2009). Redesigning business processes: A methodology based on simulation and process mining techniques. Knowledge and Information Systems, 21(3), 267-297.

Marzuoli, A., Boidot, E., Colomar, P., Guerpillon, M., Feron, E., Bayen, A., \& Hansen, M. (2016). Improving disruption management with multimodal collaborative decision-making: A case study of the asiana crash and lessons learned. IEEE Transactions on Intelligent Transportation Systems, 17(10), 2699-2717. doi:10.1109/TITS.2016.2536733

Miranda, V.A.P., Oliveira, A.V.M., 2018. Airport slots and the internalization of congestion by airlines: an empirical model of integrated flight disruption management in Brazil. Transport. Res. Pol. Pract. 116, 201219.

Jafari, N., \& Zegordi, S.H. (2010). Simultaneous recovery model for aircraft and passengers. J. Franklin Institute, 348, 1638-1655.

Profillidis, V. A., \& Botzoris, G. N. (2019). Modeling of transport demand: Analyzing, calculating, and forecasting transport demand. Amsterdam, Netherlands: Elsevier.

Protus, S. O., \& Govender, K. (2016). Managing airport service quality - the impact of self-service technologies. Investment Management \& Financial Innovations, 13(3), 387-393. doi:http://dx.doi.org.ezproxy.libproxy.db.erau.edu/10.21511/imfi.13(3-2).2016.11

T2RL report finds flight disruption costs travel industry $8 \%$ in global revenues. (2016). Airline Industry Information, Retrieved from http://ezproxy.libproxy.db.erau.edu/login?url=https://search-proquestcom.ezproxy.libproxy.db.erau.edu/docview/1830264768?accountid=27203

Voltes-Dorta, A., Rodríguez-Déniz, H., Suau-Sanchez, P., Linköpings universitet, Institutionen för datavetenskap, \& Tekniska fakulteten. (2017). Passenger recovery after an airport closure at tourist destinations: A case study of palma de mallorca airport. Tourism Management, 59, 449-466. doi:10.1016/j.tourman.2016.09.001 